\title{
STUDY OF STRESS-RELATED DISEASES IN YOGA AND OTHER FORM OF EXERCISE PRACTITIONERS
}

Megha P. Tajne1, Heena D. Pahuja², Anjali R. Bhure³, Savita M. Chauhan4, Medhana Lokhande ${ }^{5}$ Nagesh Malbhage ${ }^{6}$, Sayali Kulkarni 7 , Neha Fuladi ${ }^{8}$

${ }^{1}$ Associate Professor, Department of Anaesthesia, NKP Salve Institute of Medical Sciences, Nagpur. ${ }^{2}$ Assistant Professor, Department of Anaesthesia, NKP Salve Institute of Medical Sciences, Nagpur. 3 Professor and HOD, Department of Anaesthesia, NKP Salve Institute of Medical Sciences, Nagpur. ${ }^{4}$ Assistant Lecturer, Department of Anaesthesia, NKP Salve Institute of Medical Sciences, Nagpur. ${ }_{5}^{5}$ Assistant Professor, Department of Anaesthesia, NKP Salve Institute of Medical Sciences, Nagpur. ${ }^{6}$ Junior Resident, NKP Salve Institute of Medical Sciences, Nagpur. 7Junior Resident, NKP Salve Institute of Medical Sciences, Nagpur. 8Junior Resident, NKP Salve Institute of Medical Sciences, Nagpur.

\section{BACKGROUND}

ABSTRACT

Physical exercise is any bodily activity that enhances or maintains physical fitness and overall health. It is performed for various reasons, such as increasing growth and development, preventing ageing, strengthening muscles and the cardiovascular system, increasing athletic skills, weight loss or maintenance, and also enjoyment. There are various types of exercises such as aerobic, anaerobic, yoga, etc.

Our study aims to compare yoga and other form of exercise and its effects on stress-related diseases.

\section{MATERIALS AND METHODS}

Our study was a cross-sectional, retrospective, questionnaire-based study. 134 subjects belonged to yoga group [group Y] and 82 were in the other form of exercise group [group E]. Incidence of stress-related diseases such as Hypertension [HT], Ischaemic heart disease[IHD], Diabetes mellitus [DM], Asthma, Chronic back pain [CBP], Osteoarthritis, and Headache were found out in the two groups.

\section{RESULTS}

In yoga group, hypertensives were higher than in other exercise group. But, the subjects of IHD, DM, Asthma, chronic back pain, osteoarthritis and headache were higher in other exercise group when compared to yoga group. This difference was not statistically significant.

\section{CONCLUSION}

In our study, beneficial effects of yoga and other form of exercises are comparable with yoga group showing slight superior result.

\section{KEYWORDS}

Yoga, Physical Inactivity, Exercise, Stress, Diseases, Health Benefits of Yoga.

HOW TO CITE THIS ARTICLE: Tajne MP, Pahuja HD, Bhure AR, et al. Study of stress-related diseases in yoga and other form of exercise practitioners. J. Evolution Med. Dent. Sci. 2017;6(89):6219-6223, DOI: 10.14260/jemds/2017/1352

\section{BACKGROUND}

When challenged with any physical task the human body responds through a series of integrated changes in function that involve various systems. Movement requires activation and control of the musculoskeletal system; the cardiovascular, respiratory system, etc. When the body engages in exercise training, systems undergo specific adaptations that increase the body's efficacy and capacity.

Physical inactivity is a modifiable risk factor for cardiovascular disease and a widening variety of other chronic diseases including diabetes mellitus, cancer, hypertension, obesity, bone and joint diseases (osteoporosis and osteoarthritis), and depression. There is irrefutable evidence of the effectiveness of regular physical activity in

'Financial or Other Competing Interest': None.

Submission 04-10-2017, Peer Review 29-10-2017,

Acceptance 04-11-2017, Published 13-11-2017.

Corresponding Author:

Dr. Heena D. Pahuja,

C-302, Pritam Complex,

Old Bhandara Road, Nagpur.

E-mail: heenapahuja15@yahoo.com

DOI: $10.14260 /$ jemds/2017/1352 the primary and secondary prevention of several chronic diseases. There appears to be a linear relation between physical activity and health status, such that a further increase in physical activity and fitness will lead to additional improvement in health status. ${ }^{1}$

Yoga is an ancient discipline designed to bring balance and health to the physical, mental, emotional, and spiritual dimensions of the individual. Yoga is often depicted metaphorically as a tree and comprises eight aspects, limbs: yama [universal ethics], niyama [individual ethics], asana [physical postures], pranayama [breath control], pratyahara [control of the senses], dharana [concentration], dhyana [meditation], and Samadhi [bliss]. A growing body of evidence supports the belief that yoga benefits physical and mental health via downregulation of the hypothalamicpituitary-adrenal [HPA] axis and the sympathetic nervous system [SNS]. ${ }^{2}$ Research on yoga is rapidly proliferating, researchers are studying the effects of yoga on a wide range of mental and physical conditions. Researchers have demonstrated preliminary efficacy for many conditions including, arthritis, stress, metabolic syndrome, asthma, pain and depression. ${ }^{3}$ However, the literature is replete with many contradictory findings and generally characterised as 
inconclusive. The purpose of this article is to study the impact of yoga compared to other form of exercise on a variety of stress-related diseases such as HT, IHD, DM, Asthma, CBP, Osteoarthritis and Headache.

\section{MATERIALS AND METHODS}

The present study was conducted in a tertiary centre after taking approval of institutional ethics committee.

\section{Study Design}

It was a cross-sectional retrospective study.

Data was collected from 216 subjects from the general population who had HT, IHD, DM, Asthma, CBP, Osteoarthritis and Headache since last 10 years and were practising yoga or other form of exercise since last 5 years. They were on their regular medical drugs since last 10 years. They practised yoga like [asanas, pranayama] or any other form of exercise like [physical training, cycling, jogging, walking, running, swimming, aerobics, dancing, any sports] etc. 134 subjects turned out to be yoga practitioners [group Y] and 82 were practising other form of exercise [group E]. It was a questionnaire-based study. Incidence of stress-related diseases [hypertension, ischaemic heart disease, diabetes mellitus, asthma, chronic back pain, headache] were studied in both the groups.

\section{Statistical Analysis}

The data was collected and compiled using Epi Info Version 7.2. The quantitative variables were expressed in terms of mean and standard deviation and the qualitative variables were expressed in terms of mean and standard in proportions. Chi square test/Fisher's exact test has been used to find the difference between two proportions.

\section{RESULTS}

\begin{tabular}{|c|c|c|c|c|c|}
\hline $\begin{array}{c}\text { Age } \\
\text { Groups } \\
\text { (Years) }\end{array}$ & \multicolumn{2}{|c|}{ Group Y } & \multicolumn{2}{c|}{ Group E } & \multirow{2}{*}{ N value } \\
\cline { 2 - 5 } & Number & $\%$ & Number & $\%$ & \\
\hline $40-50$ & 56 & 69.30 & 82 & 61.20 & 0.2918 \\
\hline $51-60$ & 26 & 30.70 & 52 & 38.80 & \\
\hline Total & $\mathbf{8 2}$ & $\mathbf{1 0 0}$ & $\mathbf{1 3 4}$ & $\mathbf{1 0 0}$ & \\
\hline \multicolumn{7}{|c|}{ Table 1. Age Groups } \\
\hline
\end{tabular}

Chi square test applied.

Table 1 shows the distribution of the study subjects based on age groups. In yoga group, the majority of study subjects were in the age group of 40 to 50 years followed by 50 to 60 years. In other exercise group also, majority of study subjects were in the age group of 40-50 years followed by $50-60$ years.

\begin{tabular}{|c|c|c|c|c|c|}
\hline \multirow{2}{*}{ Gender } & \multicolumn{2}{|c|}{ Group Y } & \multicolumn{2}{c|}{ Group E } & \multirow{2}{*}{ P value } \\
\cline { 2 - 5 } & Number & $\mathbf{\%}$ & Number & $\mathbf{\%}$ & \\
\hline Male & 47 & 57.31 & 59 & 44.02 & 0.0580 \\
\hline Female & 35 & 42.68 & 75 & 55.97 & \\
\hline Total & $\mathbf{8 2}$ & $\mathbf{1 0 0}$ & $\mathbf{1 3 4}$ & $\mathbf{1 0 0}$ & \\
\hline \multicolumn{7}{|c|}{ Table 2. Gender } \\
\hline
\end{tabular}

Table 2 shows the gender wise distribution of the study subjects. The yoga group had majority of males, and the other exercise group had majority of females. But this difference was not statistically significant.

\begin{tabular}{|c|c|c|c|c|c|}
\hline Disease & \multicolumn{2}{|c|}{ Group Y } & \multicolumn{2}{c|}{ Group E } & P value \\
\hline & $\mathbf{n}$ & $\mathbf{\%}$ & $\mathbf{n}$ & $\mathbf{\%}$ & \\
\hline Hypertension & 19 & 23.17 & 23 & 17.16 & 0.2790 \\
\hline $\begin{array}{c}\text { Ischaemic heart } \\
\text { disease }\end{array}$ & 2 & 2.43 & 5 & 3.73 & 0.7117 \\
\hline Diabetes mellitus & 5 & 6.09 & 9 & 6.71 & 0.8577 \\
\hline Asthma & 2 & 2.43 & 5 & 3.73 & 0.5896 \\
\hline $\begin{array}{c}\text { Chronic low back } \\
\text { pain }\end{array}$ & 6 & 7.31 & 17 & 12.6 & 0.2143 \\
\hline Osteoarthritis & 5 & 6.09 & 11 & 8.20 & 0.5652 \\
\hline Headache & 4 & 4.8 & 9 & 6.7 & 0.5814 \\
\hline \multicolumn{7}{|c}{ Table 3 } \\
\hline
\end{tabular}

Table 3 shows the proportion of the study subjects with morbidities. In yoga group, hypertensives were higher than in other exercise group. But, the cases of IHD, DM, Asthma, chronic back pain, osteoarthritis and headache were higher in other exercise group when compared to yoga group. This difference was not statistically significant.

\section{DISCUSSION}

In research involving the health benefits of yoga and other form of exercise, exercise is the single most common intervention used as a comparison.

Ischaemic heart disease is on the increase nowadays. There are a number of risk factors associated with it. Heart rate variability [HRV] has been established as a non-invasive tool to study cardiac autonomic activity. Reduced HRV has been established as a predictor for increased risk of cardiac mortality and sudden cardiac death especially in patients after myocardial infarction.

In an interesting study, Khattab et al used 24-hour Holter monitoring to compare HRV during a $60 \mathrm{~min}$. yoga practice versus $60 \mathrm{~min}$. of park walking. They found out that the yoga practitioners exhibited greater HRV, particularly in those measures associated with parasympathetic tone, than during walking [p<0.001].4 Manchanda S C et al found out that yoga lifestyle intervention retards progression and increases regression of coronary atherosclerosis in patients with severe coronary artery disease. It also improves symptomatic status, functional class and risk factor profile. ${ }^{5}$ Vinay $\mathrm{AV}$ et al concluded that autonomic balance tilts towards parasympathetic predominance after 1 month of yoga practice. ${ }^{6}$ Central arterial stiffness is an accepted risk factor for cardiovascular disease. Courtney M Duren et al tried to evaluate arterial stiffness in middle aged adults who regularly practised yoga, performed regular exercise, or were inactive. Yoga and aerobic groups were not different in either carotid artery distensibility (DC) $(p=0.26)$ or pulse wave velocity (PWV) $(\mathrm{p}=0.21)$. The sedentary group had lower DC and higher PWV compared to the aerobic and yoga groups (both $\mathrm{p}$ $<0.001) .{ }^{7}$ In our study, we found out that the subjects who had Ischaemic heart disease was $3.73 \%$ in other form of exercise practitioners [group E] while in yoga practitioners [group Y] it was $2.43 \%$. P value was 0.7117 which was not statistically significant.

Bowman A J et al studied the effects of aerobic exercise training and yoga on the baroreflex in healthy elderly persons. They found out that Heart rate decreased following yoga $\mathrm{P}<0.05$ but not aerobic training $\mathrm{P}=0.29$. V02 max increased by $11 \%$ following yoga $(\mathrm{P}<0.01)$ and by $24 \%$ following aerobic training $(\mathrm{P}<0.01)$. No significant change in alpha MF ( $\mathrm{P}=0.69)$ or alpha HF $(\mathrm{P}=0.65)$ occurred after 
aerobic training. Following yoga, alpha HF $\mathrm{P}<0.01$ but no increase in alpha MF $\mathrm{P}=0.29$.

They found out that short duration aerobic training does not modify the alpha - index at alpha MF [sympathetic activity] or alpha HF [parasympathetic activity]. Alpha HF but not alpha MF increased following yoga, suggesting that these parameters are measuring distinct aspects of the baroreflex that are separately modifiable. ${ }^{8} \mathrm{~W}$ Selvamurthy et al demonstrated that the sluggish baroreflex mechanism observed in patients of essential hypertension can be reactivated by a 3-week course of orthostatic tilt or selected yogic postural exercises thereby restoring $\mathrm{BP}$ to normal levels. Once the sensitivity of baroreceptor mechanism is restored, it corrects all other neurohumoral malfunctioning, as observed from the reduction in sympathetic activity, plasma catecholamines, renin activity to optimal level after 3 weeks of tilt or yoga course. It also points to a close link between the baroreceptor mechanism, sympathetic activity and renin mechanisms suggesting an unifying role of baroreceptor mechanism in the aetiology of essential hypertension. ${ }^{9}$ Damodaran A et al studied the effect of yoga on the physiological, psychological wellbeing, psychomotor parameter and modifying cardiovascular risk factors in mildto-moderate hypertensive patients. Results showed decrease in BP and drug score modifying risk factors, i.e. blood glucose, cholesterol and triglycerides decrease in VMA [Vanillylmandelic acid], catecholamine, and decreased MDA [malondialdehyde] level suggestive of decrease sympathetic activity and oxidant stress. ${ }^{10}$ McCaffrey et al tried to determine the effectiveness of a yoga program on blood pressure and stress, a group of hypertensive patients in Thailand were studied, with the experimental group showing significantly decreased mean stress scores and blood pressure, heart rate, and body mass index levels compared with the control group. ${ }^{11}$ In our study, the percentage of hypertension in other form of exercise group was 17.16 while in yoga group it was 23.17, p value was 0.2790 . The difference between the two groups was not statistically significant. Our findings are consistent with the above authors in view of hypertension.

Lorenzo A Gordon et al studied the effect of exercise therapy on lipid profile and oxidative stress indicators in patients with type 2 diabetes and demonstrated the efficacy of Hatha yoga on fasting blood glucose, lipid profile, oxidative stress markers and antioxidant status in patients with type 2 diabetes and suggested that hatha yoga exercise and conventional PT exercise may have therapeutic preventive and protective effects on diabetes mellitus by decreasing oxidative stress and improving antioxidant status. ${ }^{12}$ Praveen Angadi et al studied adherence to yoga and its resultant effects on blood glucose in type 2 diabetes and demonstrated that participants who completed the yoga program had significantly lower $\mathrm{HbA}_{1 \mathrm{c}}$ (end of $3^{\text {rd }}$ month). At the end of 6 months, yoga adherence was significantly negatively correlated with blood sugar and stress. ${ }^{13}$ Heath GW et al studied the effects of exercise and lack of exercise on glucose tolerance and insulin sensitivity and demonstrated that physically trained individuals have a markedly blunted insulin response to a glucose load and yet have normal glucose tolerance. This phenomenon has generally been ascribed to longterm adaptations to training which correlate with maximal oxygen uptake (VO2 max) and reduced adiposity. Despite the increased insulin levels, blood glucose concentrations were higher after 10 days without exercise. Insulin binding to monocytes also decreased with physical inactivity. One bout of exercise after 11 days without exercise returned insulin binding and the insulin and glucose responses to an oral 100-gram glucose load almost to the initial "trained" value. ${ }^{14}$ In our study, $6.09 \%$ subjects in group $\mathrm{Y}$ had DM while it was $6.71 \%$ in group E. P value was 0.877 which was statistically not significant. Our findings are consistent with the above authors with regards to DM.

Tarun Saxena et al studied the effect of various breathing exercises (pranayama) in patients with bronchial asthma of mild-to-moderate severity and demonstrated that after 12 weeks the pranayama group subjects had significant improvement in symptoms, $\mathrm{FEV}_{1}$ and PEFR as compared to meditation group subjects. Breathing exercises (pranayama), mainly expiratory exercises, improved lung function subjectively and objectively and should be regular part of therapy. Three important things were found in their study. Firstly, expiratory exercises are helpful. In bronchial asthma expiration is difficult, so exercises that support expiration are beneficial and secondly, forceful expiratory exercises are helpful. air easily comes in and goes out in a normal person, but in an asthmatic patient air is coming in easily but during expiration there is closing of airways and force is required to open the airways; hence, a high pitch/forceful Omkara 000000000 ........MMM was found to be helpful instead of oooo..mmm. Thirdly, prolonged expiratory exercises (expiration) are helpful. During normal Omkara the air comes out only from the upper part of the airways, but asthma is a disease that affects whole lower respiratory tract, so prolonged exercise which helps to expire maximum trapped air is found beneficial. Normally, Omkara is stopped after 1015 seconds like ooooo......mmm, but the beneficial effect in asthma is found with prolonged 0000000000000 .......MMMM until further expiration is not possible. ${ }^{15}$ Agnihotri $S$ et al studied the impact of yoga on biochemical profile of asthmatics: A randomised controlled study. They demonstrated that in yoga group, there was significant improvement found in the proportion of haemoglobin and antioxidant superoxide dismutase in comparison to control group and significant decrease was found in total leukocyte count (TLC) and differential leukocyte count in comparison to control group. 16 In our study, we found out that the percentage of asthmatics in other form of exercise group was $3.73 \%$ while in yoga practitioners it was $2.43 \%$. The p value was 0.5896 which was not significant amongst the two groups. Our findings are correlating with the above authors.

Karen J. Sherman et al studied whether yoga is more effective than conventional stretching exercises or a self -care book for primary care patients with chronic low back pain. They found out that yoga classes were more effective than a self-care book, but not more effective than stretching classes, in improving function and reducing symptoms due to chronic low back pain, with benefits lasting several months. ${ }^{17}$ Galantino ML et al studied the impact of modified hatha yoga on chronic low back pain: a pilot study and demonstrated that potentially important trends in the functional measurement scores showed improved balance and flexibility and decreased disability and depression for the yoga group 
but this pilot was not powered to reach statistical significance. 18

In our study, the percentage was 12.6 in group $\mathrm{E}$ while it was $7.31 \%$ in group $\mathrm{Y}$ in subjects of chronic low backache. $\mathrm{P}$ value was 0.2143 which was statistically not significant.

John Ebenezer et al in his study concluded that an integrated approach of yoga therapy is better than therapeutic exercises as an adjunct to transcutaneous electrical stimulation and ultrasound treatment in improving knee disability and quality of life in patients with osteoarthritis knees. ${ }^{19}$ Zainab S Motorwala et al studied the effects of yogasanas on osteoporosis in postmenopausal women and demonstrated that a statistically significant difference was found in the Bone mineral density (BMD ) score. Thus, they concluded that integrated yoga is a safe mode of physical activity which includes weightbearing as well as non-weightbearing asanas, pranayama, and suryanamaskar, all of which helps induce improvement in BMD in postmenopausal osteoporotic females. ${ }^{20}$ In our study, the percentage was 8.20 in group $\mathrm{E}$ and 6.09 in group $\mathrm{Y}$ in arthritis subjects. P value was 0.5652 which was statistically not significant.

John P J et al studied the effectiveness of yoga therapy in the treatment of migraine without aura. They concluded that there was a significant reduction in migraine headache frequency and associated clinical features, in patients treated with yoga over a period of 3 months. ${ }^{21}$ In our study, $6.7 \%$ in group $\mathrm{E}$ had headache while it was $4.8 \%$ in group Y. P value was 0.5814 which was statistically not significant.

Mental stress is on the increase day by day. West J et al studied the effect of hatha yoga and African dance on perceived stress, affect and salivary cortisol. Both African dance and hatha yoga reduced perceived stress and negative affect. Cortisol increased in African dance group and decreased in hatha yoga group. Therefore, even when these interventions produce similar positive psychological effects, the effects may be very different on physiological stress processes. $^{22}$ Sushil Chandra et al studied mental stress its neurophysiology and its regulation by Sudarshan kriya yoga (SKY). The EEG, ECG and stress determination stress showed significant decrement in mental stress and improvement in cognitive performance after SKY, indicating SKY as a good alternative of medication for stress management. ${ }^{23}$ Harber VJ et al in their article reviewed that the serum concentration of endogenous opioids, in particular beta-endorphin and betalipotropin, increase in response to both acute exercise and training programs. They cause immediate mood elevation and altered perception of pain. Endogenous opioids depress ventilation and may therefore play a role in ventilatory regulation by $\mathrm{C}_{2}$, hypoxia and exercise. The yoga postures are slow rhythmic movements which emphasise the stimulation of the organs and glands by easy bending and extensions which do not overstimulate muscles but concentrate on glandular stimulation. ${ }^{24}$

Overall exercise helps to prevent depression, increase quality of sleep and act as a non-pharmaceutical sleep aid to treat diseases such as insomnia, improve mental health, maintain steady digestion and treat constipation, and augment an individual's body image for maintaining positive self-esteem.

\section{CONCLUSION}

In our study, beneficial effects of yoga and other form of exercise are comparable, with yoga group showing slight superior result. When one compares longterm yoga practitioners to people practising other form of exercise, better body awareness is observed in yoga practitioners. There are various incidences of harm caused to the body in both yoga and other form of exercise in intense and vigorous practitioners. So, taking this into consideration, the tailoring of whatever form of exercise practised should be according to the limitation of the body and its requirement.

\section{ACKNOWLEDGEMENT}

The authors wish to acknowledge and appreciate the contributions of Dr. Ranjana Deshmukh, (Dept. of Anaesthesia) in the form of constant encouragement and whole-hearted support in successful conduction of the study.

\section{REFERENCES}

[1] Warburton DE, Nicol CW, Bredin SS. Health benefits of physical activity: the evidence. CMAJ 2006;174(6):801-9.

[2] Ross A, Thomas S. The health benefits of yoga and exercise: a review of comparison studies. J Altern Complement Med 2010;16(1):3-12.

[3] Park CL, Groessl E, Maiya M, et al. Comparison groups in yoga research: a systematic review and critical evaluation of the literature. Complement Ther Med 2014;22(5):920-9.

[4] Khattab K, Khattab AA, Ortak J, et al. Iyengar yoga increases cardiac parasympathetic nervous modulation among healthy yoga practitioners. Evid Based Complement Alternat Med 2007;4(4):511-7.

[5] Manchanda SC, Narang R, Reddy KS, et al. Retardation of coronary atherosclerosis with yoga lifestyle intervention. J Assoc Physicians India 2000;48(7):68794.

[6] Vinay AV, Venkatesh D, Ambarish V. Impact of shortterm practice of yoga on heart rate variability. Int J Yoga 2016;9(1):62-6.

[7] Duren CM, Cress ME, McCully KK. The influence of physical activity and yoga on central arterial stiffness. Dyn Med 2008;7:2.

[8] Bowman AJ, Clayton RH, Murray A, et al. Effects of aerobic exercise training and yoga on baroreflex in healthy elderly persons. Eur J Clin Invest 1997;27(5):443-9.

[9] Selvamurthy W, Sridharan K, Ray US, et al. A new physiological approach to control essential hypertension. Indian J Physiol Pharmacol 1998;42(2):205-13.

[10] Damodaran A, Malathi A, Patil N, et al. Therapeutic potential of yoga practices in modifying cardiovascular risk profile middle aged men and women. J Assoc Physicians India 2002;50(5):633-40.

[11] McCaffrey R, Ruknui P, Hatthakit U, et al. The effects of yoga on hypertensive persons in Thailand. Holist Nurs Pract 2005;19(4):173-80. 
[12] Gordon LA, Morrison EY, McGrowder DA, et al. Effects of exercise therapy on lipid profile and oxidative stress indicators in patients with type 2 diabetes. BMC Complement Altern Med 2008;8:21.

[13] Angadi P, Jagannathan A, Thulasi A, et al. Adherence to yoga and its resultant effects on blood glucose in type 2 diabetes: a community-based follow-up study. Int J Yoga 2017;10(1):29-36.

[14] Heath GW, Gavin JR, Hinderliter JM, et al. Effects of exercise and lack of exercise on glucose tolerance and insulin sensitivity. J Appl Physiol Respir Environ Exerc Physiol 1983;55(2):512-7.

[15] Saxena T, Saxena M. The effect of various breathing exercises (pranayama) in patients with bronchial asthma of mild to moderate severity. Int J Yoga 2009;2(1):22-5.

[16] Agnihotri S, Kant S, Kumar S, et al. Impact of yoga on biochemical profile of asthmatics: a randomized controlled study. Int J Yoga 2014;7(1):17-21.

[17] Sherman KJ, Cherkin DC, Wellman RD, et al. A randomized trial comparing yoga, stretching, and self care book for chronic low back pain. Arch Intern Med 2011;171(22):2019-26.
[18] Galantino ML, Bzdewka TM, Holbrook ML, et al. The impact of modified hatha yoga on chronic low back pain: a pilot study. Altern Ther Health Med 2004;10(2):56-9.

[19] Ebnezar J, Nagarathna R, Bali Y, et al. Effect of an integrated approach of yoga therapy on quality of life in osteoarthritis of knee joint: a randomized control study. Int J Yoga 2011;4(2):55-63.

[20] Motorwala ZS, Kolke S, Panchal PY, et al. Effects of yogasanas on osteoporosis in postmenopausal women. Int J Yoga 2016;9(1):44-8.

[21] John PJ, Sharma N, Sharma CM, et al. Effectiveness of yoga therapy in the treatment of migraine without aura: a randomized controlled trial. Headache 2007;47(5):654-61.

[22] West J, Otte C, Geher K, et al. Effects of hatha yoga and African dance on perceived stress, affect and salivary cortisol. Ann Behav Med 2004;28(2):114-8.

[23] Chandra S, Jaiswsal AK, Singh R, et al. Mental stress: neurophysiology and its relation by sudarshan kriya yoga. Int J Yoga 2017;10(2):67-72.

[24] Harber VJ, Sutton JR. Endorphins and exercises. Sports Med 1984;1(2):154-71. 